\title{
LOCAL MECHANICAL PROPERTIES OF ATMOSPHERIC SPRAYED MOLYBDENUM COATINGS DEPOSITED WITH CASCADED PLASMA TORCH
}

\author{
Jakub Antoš ${ }^{a, *}$, Petra Šulcová $^{a}$, Kateřina Lencováa ${ }^{a}$,

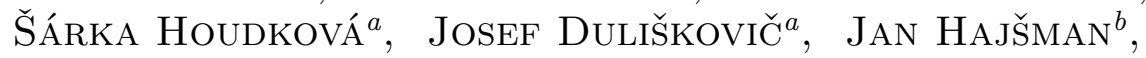 \\ KAROLÍnA BuRdová ${ }^{b}$, AnTONÍN RAČICKÝ $^{b}$ \\ ${ }^{a}$ Research and Testing Institute, Tylova 1581/46, 30100 Plzeň, Czech Republic \\ ${ }^{b}$ University of West Bohemia, Univerzitni 8, 30614 Plzeñ, Czech Republic \\ * corresponding author: antos@vzuplzen.cz
}

\begin{abstract}
Increasing interest for industrial use of thermally sprayed coatings leads to development in most thermal spraying technologies, including atmospheric plasma spraying (APS). The latest cascaded torch SinplexPro from Oerlikon Metco incorporates the efficiency advantages of cascaded arc technology into a single-cathode spray gun. It leads to more stable plasma arc across a wide range of gas flows, mixtures and pressures and also highly increases powder throughput. Thermal sprayed molybdenum coatings are widely used for improving wear resistance and sliding properties in many mechanical applications. Results of pure molybdenum coatings sprayed with cascaded plasma torch are not yet fully investigated. In this paper, mechanical properties of atmospheric plasma sprayed molybdenum coatings on steel (S235) substrate are evaluated. Optimization of spraying parameters for spherical Mo powder sprayed by cascaded plasma torch SinplexPro is carried out and the influence on final microstructure, mechanical and tribological properties of molybdenum coatings is analysed.
\end{abstract}

KEYWORDS: Atmospheric plasma spraying, cascaded plasma torch, mechanical and tribological properties, molybdenum coatings.

\section{INTRODUCTION}

Atmospheric plasma spraying (APS) technology is widely used for spraying of function layers. Plasma arc technology offers high temperature and fast and stable flow of plasma jet. High temperature is required for melting and consequential efficient deposition of refractory metals, ceramics and cermets. Capability to deposit such materials makes plasma spraying particularly suitable for the production of wear resistant coatings, corrosion protective layers and thermal barriers [1. Molybdenum layers are used in many industry applications for its wear and scuff resistance and to reduce friction between sliding components 2 . Whereas the spraying of pure molybdenum and molybdenum alloys by conventional plasma torches has been closely investigated in the past (e.g. Ref. [2-4), molybdenum spraying with cascaded plasma torch is not yet fully examined.

This paper concerns spraying of pure spherical industrial grade molybdenum powder Amdry 313X by Oerlikon Metco by cascaded plasma arc torch SinplexPro. Correlation between spraying parameters and mechanical and structural properties of molybdenum coating on mild steel substrates are investegated and the optimization of spraying parameters of molybdenum powder for plasma torch SinplexPro is carried out.

Industrial APS with conventional torches is often struggling with reproducibility and reliability [5]. This is caused due to the instability of arc and subsequent oscilation of the output power level of the conventional torch during spraying process. Sinplex Pro cascaded torch deals with this issue by stacking copper rings insulated one from each other into a cascade. Those rings are called neutrodes. The whole cascade of neutrodes is positioned between cathode and the nozzle, which serves as an anode. Electric arc developing in such configuration is more stable and reduces almost all problems of conventional torches [5-7].

\section{Setup OF EXPERIMENT}

In this experiment, argon is used as the primary gas and hydrogen as the secondary gas. Argon and hydrogen are mixed to form plasma gas. This mixture runs through the electric arc, dissociating and ionizing into high temperature plasma current. Rapid increse of temperature up to $14000 \mathrm{~K}$ [1] is accompanied by substantional volume expansion. After plasma current leaves the torch, spraying material in form of a fine powder is injected into the plasma jet. Argon is commonly used as the carrier gas for the powder. Plasma jet transfer both thermal and kinetic energy into the particels. Melted and accelerated particles are deposited on the substrate material [1].

In the first stage of design of this experiment, it was required to choose variable parametrs among all process parameters of spraying. Main process parameters of Sinplex Pro system are as follows: diameter 
of torch nozzle, plasma current, primary gas flow and secondary gas flow. These four parameters take critical role in forming of plasma jet - they determine both temperature and plasma current velocity, thus directly affecting melting of the particles and their velocity. Secondary process parametrs are spraying distance, relative movement speed of the torch over the sprayed specimen, mass flow of the powder and carrier gas flow.

According to Ref. [2, 3] concerning the influence of process variables, three critical parameters were determined: velocity of particles $\left(v_{p}\right)$, temperature of particles $\left(T_{p}\right)$ and temperature of substrate $\left(T_{s}\right)$. Those three parameters have the most significant effect on the forming of the layer as well as its final properties. The state of particles described by velocity and temperature express its kinetic an thermal energy state. Among the setup parameters, the electric current has the most determinating effect on the output power level and temperature of the plasma jet and thus directly affecting the particle temperature and melting. Plasma gas flow rate as another main setup parameter has crucial effect on the velocity of the particles, and secondary effect on the plasma jet temperature. Substrate temperature as the last critical parameter is a result of combined effects of plasma jet conditions, spraying pattern, torch movement speed, spraying distance, eventual cooling cycles and the dimensions and thermal properties of the substrate istelf. It should be noted that the previous statements about influence of main setup parameters (current, gas flow, spraying distance etc.) on the three critical parameters $\left(\mathrm{v}_{\mathrm{p}}, \mathrm{T}_{\mathrm{p}}, \mathrm{T}_{\mathrm{s}}\right)$ are simplified in order to briefely describe the main effect of each setup parametr. In reality all setup parameters take effect in a most complex manner as one dynamic system, simultaneously influencing each others as well as all ciritcal parameters.

For this reason it is essential, in order to simplify the experiment, to reduce the number of variable parametrs. In the design stage of experiment it was decided to use $9 \mathrm{~mm}$ diameter torch nozzle and constant spraying distance of $125 \mathrm{~mm}$. Main reason for choosing the $9 \mathrm{~mm}$ nozzle (the largest diametr of commercially availible nozzles) is economical aspect. According to Ref. [8, larger nozzle diametr increases spraying power output, improving the spraying process efficiency and leading to faster and thus more economical spraying times. The choosing of constant spraying distance may be considered questionable, because the impact of different spraying distances on the final properties of the sprayed layers could be substantial. As mentioned in Ref. 4, increasing the spraying distance generally leads to higher hardness, which possitively correlates with wear ressistance but may not have possitive influence on the fritcion and sliding properties. This hardness growth happens due to the increased level of oxidized particles that is because of longer exposure time of melted particles to the am- bient atmosphere. The amount of oxidized particles is again not only funciton of the spraying distance alone, but comes in a complex system with other input parametrs - especially powder feed rate, grain size, plasma jet velocity and temperature etc. Overall, in order to clarify the basic relations in setup parameters - properties, it was decided to maintain constant spraying distance during the experiment 345 .

Another constant parameters was powder feed rate (63 grams per minute) and carrier gas flow rate (6 nlpm). Also secondary plasma gas (hydrogen) flow rate was set on constant level for the whole experiment (5 nlpm).

After setting most setup parameters to constant levels, electric current and primary gas flow rate was the only two parameters left to vary. Table 1 displays the chosen combinations of those two parameters for the experiment. Current varried between $350 \mathrm{~A}$ and $600 \mathrm{~A}$ in $50 \mathrm{~A}$ intervals, while primary gas flow rate between three levels - 40, 50 and $60 \mathrm{nlpm}$. Not all sets of those parameter were included. To decide which sets should be sprayed, a CPSP (critical plasma spraying parametr 9 11]) parameter was used to determine the thermal state of plasma jet for particular set of conditions. CPSP is defined as the ratio between the torch input power and primary plasma gas flow rate [10]. From all the possible combination of parameters, ten final parameter sets were chosen in order to fill the interval of CPSP between 0.5 and 1.4.

All specimens were degreased and grid blasted shortly before the spraying process. Spraying took place in a plasma spraying chamber of Research and Testing Institute Pilsen. Conditions for all spraying were the same, using same batch of the powder, same spraying program and also all equipment remained the same for all spraying sets. Temperature monitoring was conducted during spraying process in order to prevent overheating of the substrate and eventual cooling cycles were included. Ten passes of the torch were used on all sets.

\section{Testing Methods}

Layer thickness, surface roughness and macro hardness HR15N were measured on all sprayed specimens. Layer thickness was measured as a difference between specimen thickness before and after coating deposition process and cooling to the ambient temperature using micrometer screw gauge. The measured thickness was double checked using optical metallography measurement on the scratch pattern. Scratch patterns of samples from all sets were inspected and photographed using optical microscopy. All samples also underwent scanning electron microscopy and EDS analysis.

Adhesive strength of coating to the substrate was evaluated according to ISO EN 14916 on specimens from 3 chosen set of parameters.

A major effort was devoted to the detailed measurement of hardness and modulus of molybdenum coatings. Rockwell hardness test HR15N was employed 

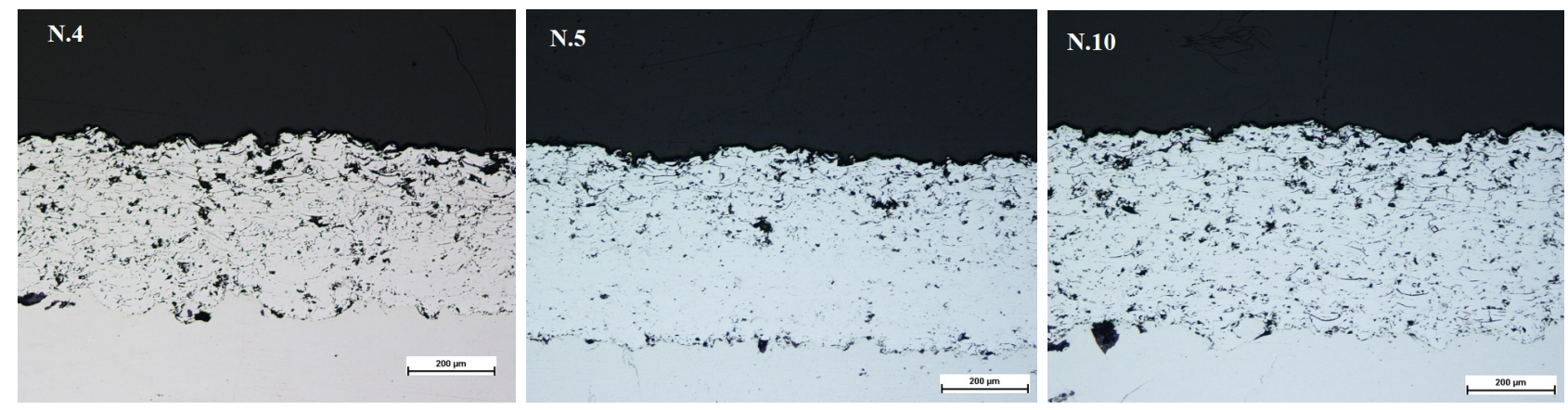

Figure 1. Microstructure of samples from selected sets (100x).

\begin{tabular}{|c|c|c|c|}
\hline \multirow{2}{*}{ INPUT CURRENT } & \multicolumn{3}{|c|}{ PRIMARY GAS FOW RATE } \\
\hline & Ar $40 \mathrm{nlpm}$ & Ar $50 \mathrm{nlpm}$ & Ar $60 \mathrm{nlpm}$ \\
\hline $350 \mathrm{~A}$ & & & $\begin{array}{c}\text { CPSP } 0.5 \\
\text { N. } 1\end{array}$ \\
\hline $400 \mathrm{~A}$ & & & $\begin{array}{l}\text { CPSP } 0.6 \\
\text { N. } 2\end{array}$ \\
\hline $450 \mathrm{~A}$ & $\begin{array}{c}\text { CPSP } 1.1 \\
\text { N. } 9\end{array}$ & $\begin{array}{c}\text { CPSP } 0.9 \\
\quad \text { N. } 7\end{array}$ & $\begin{array}{c}\text { CPSP } 0.7 \\
\quad \text { N. } 3\end{array}$ \\
\hline $500 \mathrm{~A}$ & & & $\begin{array}{c}\text { CPSP } 0.8 \\
\text { N. } 4\end{array}$ \\
\hline $550 \mathrm{~A}$ & & & $\begin{array}{c}\text { CPSP } 0.9 \\
\text { N. } 5\end{array}$ \\
\hline $600 \mathrm{~A}$ & $\begin{array}{c}\text { CPSP } 1.4 \\
\text { N. } \mathbf{1 0}\end{array}$ & $\begin{array}{c}\text { CPSP } 1.2 \\
\quad \text { N. } 8\end{array}$ & $\begin{array}{c}\text { CPSP } 1 \\
\text { N. } 6\end{array}$ \\
\hline
\end{tabular}

TABLE 1. Matrix of chosen variable parameters for experiment. Cells displays a serial number and an estimated value of CPSP for particular set of spraying parameters

on the polished surface of each specimen. Tests concerning Vickers hardness included HV0.3 for random measurement on scratch pattern and indentation map of HV0.1, which was used to measure hardness as a function of distance from the surface of the coating. Nanoindentation with Berkovich tip for hardness measurement and for evaluation of modulus was carried out in two layers - 150 microns underneath the surface and 150 microns above substrate. Rather large indentation force of $5 \mathrm{~N}$ was required in order to obtain indents large enough to cover a representative area of coating including all typical coating formations. Smaller indents would have measured only properties of splats, oxide layers or unmleted particles alone.

Hardness tests HR15N and HV0.3 were performed on specimens from all sets of parameters, whereas HV0.1, nanoindentation, Indentation Fracture Toughness test (IFT) and Ball-on-Flat tests were performed on three chosen sets. The three sets that underwent more detailed test were chosen according to CPSP values and microstructure in order to represent three typically obtained structures.

Ball-on-Flat tribological test according to ASTM G-133 standard was performed on three chosen sets (N.4, N.5 and N.10). Dry contact conditions, $25 \mathrm{~N}$ normal force, length of track $10 \mathrm{~mm}, 5 \mathrm{~Hz}$ cycling frequency and $1000 \mathrm{~s}$ test duration was used. Stainless steel ball of $62 \mathrm{HRC}$ and $6.3 \mathrm{~mm}$ diameter was used against the polished surface of tested samples. Three tests were performed on each specimen. The tracks left after this test were measured with a profilometer device to obtain volume loss values and underwent detailed SEM screening and EDS testing to clarify the tribological processes.

\section{RESUlts AND DisCUSSION}

\subsection{Microstructure}

Based on comparison of microstructure images, three sets were chosen for further testing: N.4, N.5 and N.10 (see 3 TESTING METHODS). Images from optical microscopy of those three sets are shown above (Fig. 1).

\subsection{HARDNESS AND MODULUS}

Results of HR15N surface measurement showed only small differences between individual sets, mostly in magnitude of standard deviation.

HV0.3, HV0.1 as well as nanoindentation were performed on specimens of three chosen sets, with 10 random indents each. Fig. 2 shows progression of HV0.1 as a function of distance from the coating surface. N.5 displayed a distinctive compact structure of bottom half of the coating (no pores were visible and splat boundaries were more difficult to recognize 


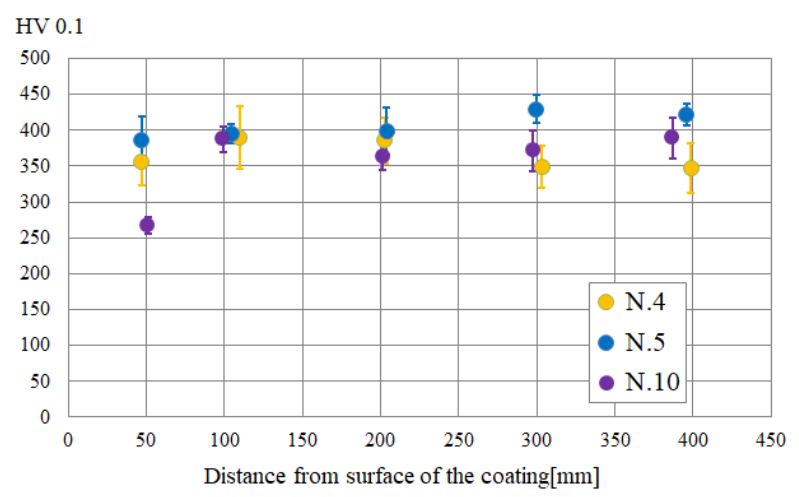

Figure 2. Results of HV0.1 indentation as a function of distance from surface.

using the optical microscopy). This compact layer is accompanied with an increase in hardness. Specimens representing N.4 and N.10 lacks this compact layer. N.10 represents the most porous and coarse microstructre of the three chosen sets, while N.4 is finer, with smaller and more evenly located pores.

Tab. 2 displays the results of nanoindentation, where values are highlighted by colored columns. It showed that N.5 containing visible bottom compact layer has the highest modulus and hardness in both measured layers (below surface and above substrate). Especially significant increase in modulus implies that N.5 has the largest residual compressive stress, especialy in the compact layer 11. This may happen due to the rather large input power level combined with high flow rate of plasma gas.

\begin{tabular}{|c|l|l|l|l|l|}
\hline \multirow{2}{*}{$\begin{array}{c}\text { Set } \\
\text { number }\end{array}$} & \multicolumn{1}{|c|}{ CPSP } & \multicolumn{2}{|c|}{ Hardness [GPa] } & \multicolumn{2}{c|}{ E [GPa] } \\
\cline { 2 - 6 }$[\mathrm{kW} / \mathrm{slpm}]$ & $\begin{array}{l}150 \mu \mathrm{m} \text { above } \\
\text { substrate }\end{array}$ & $\begin{array}{l}150 \mu \mathrm{m} \text { below } \\
\text { surface }\end{array}$ & $\begin{array}{l}150 \mu \mathrm{m} \text { above } \\
\text { substrate }\end{array}$ & $\begin{array}{l}150 \mu \mathrm{mm} \text { below } \\
\text { surface }\end{array}$ \\
\hline N.4 & 0,83 & 2,86 & 3,41 & 77 & 103 \\
\hline N.5 & 0,93 & 3,39 & 3,76 & 103 & 139 \\
\hline N.10 & 1,41 & 2,67 & 2,89 & 92 & 93 \\
\hline
\end{tabular}

TABLE 2. Resulst of nanoindentation correlated to CPSP parametr

\subsection{TRIBological Properties}

Results of Ball-on-Flat test performed on the three representative types showed two stages of dry friction contact (see Fig. 3). In the first stage there was an increasing progress of coefficient of friction (COF). This initial stage lasted about $350 \mathrm{~s}$ for N.4 and N.5 and around $280 \mathrm{~s}$ for N.10. After this period of time, sudden drop in COF appeared and the progress remained constant and stable for the rest of the test. SEM images with EDS analyses implied, that the main mechanism for this COF decrease was creation of oxidized films. With the shortest initial period, N.10 also displayed lowest COF value of all tested specimens for both stages - 0.64 in the first stage following a drop to 0.62 . N.4 and N.5 COF values were 0.68 (dropping to 0.66 ) and 0.7 (dropping to 0.67)

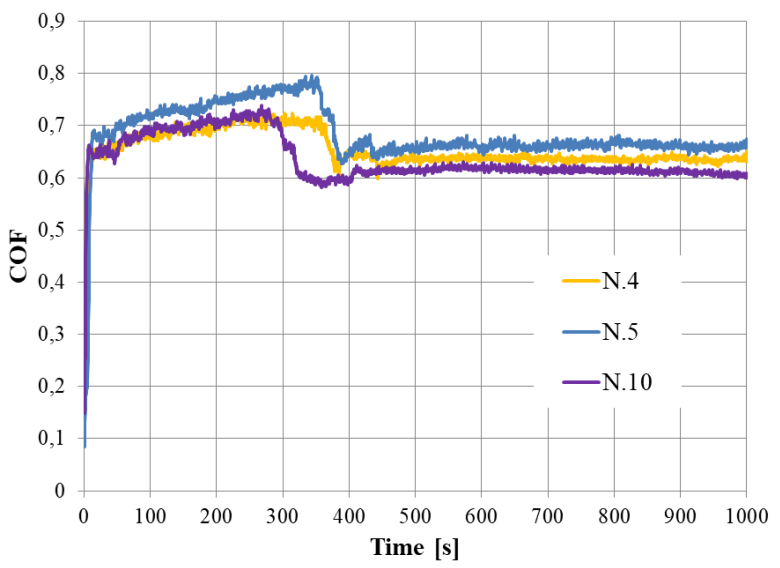

Figure 3. Comparison of COF progress of Ball-onFlat tested specimens. Note: for illustration only one track for every specimen is displayed

respectively. Those results correspond to wear coefficient K, which was similar for N.4 and N.5 - 1.67e-4 and $1.91 \mathrm{e}-4 \mathrm{~mm}^{3} / \mathrm{Nm}$ respectively. N.10 showing the lowest $\mathrm{COF}$ values also displayed significantly lower $\mathrm{K}$, valuing $1.1 \mathrm{e}-4 \mathrm{~mm}^{3} / \mathrm{Nm}$ - it is $34 \%$ less to $\mathrm{N} .4$ and $42 \%$ less to N.5. This difference in $\mathrm{K}$ value may be partly contributed to the difference in the duration of the first COF progression period, where presumably most material removal occurred.

\section{Conclusions}

Results of experiment showed, that with increasing power input also grows mechanical properties - hardness and modulus. Higher plasma gas throughput has the similar effect. The increase in modulus can be a result of the increase in residual stress, with higher modulus indicating higher compressive stress [11. As implied in Ref. 12 that higher deposition temperature leads to increase in splat cohesion and thus higher modulus. Higher deposition temperature also shifts the stress towards compression. All those aspects are already known and have been described in detail in the past. Therefore these knowledges can be successfully applied to design mechanical properties of plasma sprayed molybdenum with cascaded torch as well. However, as the main industrial application for molybdenum coatings is wear resistance and sliding properties, the principal property for designing the coating should be also its final wear resistance and sliding properties. Therefor sets of parameters represented by specimen N.10, although not having the highest hardness nor modulus, can be proclaimed as the best tested coating for the required industrial applications. Structure of this coating with the best $\mathrm{COF}$ and wear resistance was achieved with high power level of the plasma jet of $600 \mathrm{~A}$, and rather low primary argon flow rate of $40 \mathrm{nlpm}$. As a result of those parameters, an increase in oxidation level can be expected in this coating compared to others, but EDS analyse did not indicate any relevant difference. 


\section{ACKNOWLEDGEMENTS}

The paper has originated in the framework of project no. TJ02000135.

\section{REFERENCES}

[1] M. I. Boulos, P. Fauchais, J. Heberlein, et al. Thermal plasma technology. vol. 2. International Union Of Pure And Applied Chemistry, 1999.

[2] An integrated study of thermal spray process-structure-property correlations: A case study for plasma sprayed molybdenum coatings. Materials Science and Engineering A, Structural Materials: Properties, Microstructure and Processing 403, 2005. DOI:10.1016/j.msea.2005.04.056

[3] S. Sampath, X. Jiang, A. Kulkarni, et al. Development of process maps for plasma spray: case study for molybdenum. Materials Science and Engineering: A 348(1):54 - 66, 2003. DOI:10.1016/S0921-5093(02)00642-1

[4] T. Stolarski, S. Tobe. The effect of spraying distance on wear resistance of molybdenum coatings. Wear 249(12):1096 - 1102, 2001. DOI:10.1016/S0043-1648(01)00842-0

[5] R. Chidambaram Seshadri, S. Sampath. Characteristics of Conventional and Cascaded Arc Plasma Spray-Deposited Ceramic Under Standard and High-Throughput Conditions. Journal of Thermal Spray Technology 28(4):690-705, 2019. DOI:10.1007/s11666-019-00841-9.
[6] OERLIKON METCO. Plasma Spray Gun SinplexPro: User manual. 2018.

[7] An introduction to thermal spray. bro-0005.6 . oerlikon metco, july 2016. issue 6 .

[8] S. T. Aruna, N. Balaji, J. Shedthi, V. K. W. Grips. Effect of critical plasma spray parameters on the microstructure, microhardness and wear and corrosion resistance of plasma sprayed alumina coatings. Surface \& coatings technology 2012. DOI:10.1016/j.surfcoat.2012.08.016

[9] D. Zhao, F. Luo, W. Zhou, D. Zhu. Effect of critical plasma spray parameter on complex permittivity and microstructure by plasma spraying $\mathrm{cr} / \mathrm{al} 2 \mathrm{o} 3$ coatings. Applied surface science 2013. DOI:10.1016/j.apsusc.2012.10.061

[10] S. Yugeswaran, V. Selvarajan, D. Seo, K. Ogawa. Effect of critical plasma spray parameter on properties of hollow cathode plasma sprayed alumina coatings. Surface and Coatings Technology 203(1):129 - 136, 2008. DOI:10.1016/j.surfcoat.2008.08.030

[11] J. Matejicek, S. Sampath, D. Gilmore, R. Neiser. In situ measurement of residual stresses and elastic moduli in thermal sprayed coatings: Part 2: processing effects on properties of mo coatings. Acta Materialia 51(3):873 - 885, 2003. DOI:10.1016/S1359-6454(02)00477-9. 